\title{
ORNAMENTAL BROMELIADS OF LOCAL BOTANICAL GARDENS SERVE AS PRODUCTION SITES FOR PYRETHROID-RESISTANT CULEX QUINQUEFASCIATUS (SAY) IN COLLIER COUNTY, FLORIDA
}

\author{
ALEXANDRIA S. WATKINS ${ }^{1,2}$, EMORY BABCOCK ${ }^{1,3.4}$, KEIRA J LUCAS ${ }^{\text {* }}$ \\ ' Collier Mosquito Control District, 600 North Road, Naples, FL, USA \\ ${ }^{2}$ Florida Gulf Coast University, Fort Myers, FL, USA
}

${ }^{3}$ School of Public Health and Tropical Medicine, Tulane University, New Orleans, LA, USA
${ }^{4}$ CDC Southeastern Center of Excellence in Vector Borne Disease, Gainesville, FL, USA

* To whom correspondence can be addressed:

Keira J. Lucas, E-mail: klucas@cmcd.org

\section{Subiect Editor: Derrick Mathias}

\begin{abstract}
The Naples Botanical Garden, located in Collier County, Florida, attracts over 220,000 visitors each year. The gardens house a collection of plants from around the world, including a featured area for over 100 species of exotic and native bromeliads. Ornamental bromeliads have previously been investigated to define their "tank" structure as a haven for mosquito eggs and larvae. The Naples Botanical Gardens was investigated for the presence of juvenile mosquitoes inhabiting large-tanked bromeliads. A survey of mosquito species inhabiting bromeliads in the gardens indicated that the most abundant species was Culex quinquefasciatus. With the ongoing threat of vector borne diseases such as West Nile virus, the abundance of vector mosquitoes and heavy tourist traffic in the gardens, insecticide resistance testing was performed on $C x$. quinquefasciatus originating in the gardens in order to assess the ability of pyrethroid-based insecticides used by the local vector control agency to successfully target this species in the event of a disease outbreak. We identified pyrethroid resistance in Cx. quinquefasciatus collected from Naples Botanical Gardens, and that oxidase activity was the primary mechanism responsible for its pyrethroid resistance status.
\end{abstract}

Key Words: bromeliads, botanical gardens, Culex quinquefasciatus, insecticide resistance, pyrethroids

\section{INTRODUCTION}

Florida has seen an increase of imported and local transmission of mosquito-borne disease in recent years. Aedes aegypti (L.) and Aedes albopictus (Skuse) represent important vectors responsible for recent outbreaks of Zika virus (McAllister et al 2020) and dengue virus (Graham et al 2011, FLDOH 2020) in Florida. Furthermore, the state is endemic with several arboviruses transmitted by Culex mosquitoes, including West Nile virus (Blackmore et al 2001) and St. Louis encephalitis virus (Harwood et al 1979).
Current disease vector control strategies rely on a combination of integrated pest management (IPM) approaches, including the application of insecticides targeting both the juvenile and adult stages. Therefore, it is crucial for vector control agencies to recognize potential disease vector habitat and identify best management practices in a time where resistance to control materials is on the rise.

Exotic and native ornamental bromeliads are a popular choice for urban residential and commercial landscaping in Florida due to their tropical esthetics and easy care. Bromeliads have previously been investigated to 
distinguish them as a production site for juvenile mosquitoes due to their water-holding "tank" structure, which can serve as a haven for mosquito eggs and larvae. Recent studies in Miami-Dade County have revealed Ae. $a e$ gypti successfully propagates within tank-type bromeliads and are the dominant species found in ornamental bromeliads in urban environments (Wilke et al 2018, Wilke et al 2019, Wilke et al 2020). In order to assess the relationship between disease vector mosquito species and bromeliads in Collier County, Florida, the Collier Mosquito Control District began a district-wide survey of mosquito species found in bromeliads within urban residential and commercial settings, as well as high-traffic tourist destinations.

The Naples Botanical Garden located in Collier County, Florida attracts over 220,000 visitors and tourists each year. The gardens house a collection of plants from around the world and includes a featured area for over 100 species of exotic and native bromeliads. With the influx of tourists in the area, the Naples Botanical Gardens was investigated for species diversity to identify the presence of disease vector mosquitoes in their largetanked bromeliads. Furthermore, due to the identification of pyrethroid-resistant Ae. $a e$ gypti (Estep et al 2018) and Cx. quinquefasciatus (Lucas et al 2020) in Collier County, pyrethroid-resistance status and mechanisms underlying resistance were assessed for the most abundant disease vector species in the gardens.

\section{MATERIALS AND METHODS}

Bromeliad survey. From May 2019 to October 2019 the Naples Botanical Gardens were routinely visited for operational inspections to survey for the presence of immature stages of mosquitoes in their exotic largetank bromeliad collections. Inspection dates were subject to availability of operations personnel and attempted weekly subject to weather. Bromeliad water reservoir tanks were drained with the aid of manual plastic pumps (turkey basters). Juvenile mosquitoes were brought back to the laboratory and larvae were identified by morphology using taxonomic keys. Total number of each species collected was recorded, and sample volumes were then normalized to the volume of a standard larval dipper $(350 \mathrm{~mL})$ (BioQuip Products Inc., Rancho Dominguez, CA). After identifying and counting mosquito larvae, mosquitoes were brought back to the insectary regulated at $28^{\circ} \mathrm{C}, 80 \%$ relative humidity and a constant light/dark (14 h $10 \mathrm{~h}$ ) cycle. Species richness (S) (the number of mosquito species present) was determined and abundance $(\mathrm{P}(\mathrm{i}))$ (proportion of the total number of $\mathrm{i}^{\text {th }}$ species) was calculated in Microsoft Excel for each collection date.

It is important to note that in August the Naples Botanical Gardens had treated their bromeliads with Merit 75WSP (AI: Imidacloprid) (Bayer Environmental Science, Cary, NC) for the Mexican Bromeliad Weevil, likely resulting in a crash of juvenile mosquito production from the bromeliads. While the gardens were still visited weekly, mosquito larvae were not detected until mid-October. Further, mosquito larvae were not identified in high enough abundance after mid-October to warrant operational inspections.

Insecticide susceptibility tests. The susceptibility to pyrethroids of Cx. quinquefasciatus collected from Naples Botanical Gardens was evaluated using the Centers for Disease Control and Prevention (CDC) bottle bioassay protocol (Brogdon and McAllister 1998a; Brogdon and Chan 2010; CDC 2020) as previously described (Lucas et al 2020). Adult female Cx. quinquefasciatus 3-5 days old were used for the assays. Three assay bottles using approximately 20-25 female mosquitoes each were exposed to the CDC diagnostic dose of the technical grade insecticides of either d-phenothrin (Sumithrin $\left.{ }^{\circledR}\right)(22 \mathrm{ug} /$ $\mathrm{mL})$, pyrethrum $(15 \mathrm{ug} / \mathrm{mL})$ or naled $(2.25$ $\mathrm{ug} / \mathrm{mL}$ ) (CDC, 2017); acetone was used as a control treatment. Mosquitoes were also exposed to the formulated products, Anvil $10-10^{\circ}$ (10\% Sumithrin, 10\% PBO) (Clarke Inc., St. Charles, IL), Merus $3.0^{\circ}$ (5\% pyrethrins) (Clarke Inc., St. Charles, IL) and Dibrom $^{\circ}$ Concentrate $(87.4 \%$ naled) (AMVAC Chemical Corp., New Port Beach, CA). Formulated products were diluted in acetone to yield the equivalent CDC diagnostic dose of 
active ingredient. Knockdown was recorded at $10 \mathrm{~min}, 15 \mathrm{~min}$ and then every $15 \mathrm{~min}$ for $2 \mathrm{~h}$ with the exception of Dibrom/Naled which was recorded every $15 \mathrm{~min}$ for 2 hr. The published CDC diagnostic time for technical grade insecticides against the susceptible Cx. quinquefasciatus Sebring colony was used for classification of resistance status (CDC, 2017). Diagnostic times for formulated products were not developed, and instead the corresponding times for technical grade insecticides were used as reference. Collections were classified as resistant or susceptible using the World Health Organization (WHO) guidelines (WHO 2013; CDC 2020): $98 \%-100 \%$ mortality at the recommended diagnostic time indicates susceptibility; $80 \%-97 \%$ mortality at the recommended diagnostic time suggests developing resistance, $<80 \%$ mortality at the recommended diagnostic time suggests resistance. Percent mortality was determined using a modified formula from Abbott (1925) and an average was produced between the three technical replicates. Graphical analysis was produced using GraphPad Prism 8 (GraphPad Software, San Diego, CA).

Phenotypic expression of knockdown resistance $(\boldsymbol{k d} \boldsymbol{r})$. A variation of the CDC Bottle Bioassay can be used to determine if a target site mechanism, such as the presence of the $k d r$ allele that results in an amino acid substitution in the voltage-gated sodium channel, contributes to the resistance status (CDC 2020). In this way, phenotypic expression of $k d r$ resistance can be determined by evaluating a population for recovery 24 $\mathrm{h}$ post-treatment. Another round of bottle bioassays were performed on Cx. quinquefasciatus collected from the Naples Botanical Gardens to assess phenotypic expression of knockdown resistance $(k d r)$ by allowing mosquitoes to recover for $24 \mathrm{~h}$ post-exposure according to CDC guidelines (CDC 2020) and as previously described (Lucas et al 2020). Three assay bottles using approximately 2025 female mosquitoes each were exposed to the CDC diagnostic dose of the technical grade insecticides of either d-phenothrin (Sumithrin), pyrethrum or naled, as described above. After $2 \mathrm{~h}$, all exposed mosqui- toes were transferred to holding cages and provided a $20 \%$ sucrose solution. Mortality was recorded at $24 \mathrm{~h}$ post-exposure. Percent recovery was determined, and an average was produced between the three technical replicates as previously described (Lucas et al 2020). Graphical analysis was produced using GraphPad Prism 8.

Analysis of metabolic resistance. Similar to identifying resistance attributed to targetsite-mutations, a variation of the CDC Bottle Bioassay using enzyme inhibitors can be used to determine resistance attributed to metabolic detoxification enzymes (Brogdon and McAllister 1998b; CDC 2020). In order to assess the effect of metabolic resistance in $C x$. quinquefasciatus mosquitoes collected from Naples Botanical Gardens, synergists were used according to the protocol described by the CDC (Brogdon and McAllister 1998b; CDC 2020). Three technical replicates of approximately 20-25 mosquitoes were exposed to one of the three synergists: S.S.Stributylphosphorotrithioate (DEF) (125 $\mathrm{g}$ / bottle), which inhibits esterase activity; diethyl maleate (DEM) $(80 \mu \mathrm{g} /$ bottle), which inhibits glutathione transferase activity; and piperonyl butoxide (PBO) (400 $\mu \mathrm{g}$ /bottle), which inhibits oxidase activity. Mosquitoes were exposed to synergists for one hour, transferred to holding cages for recovery for another hour and then used in a bottle bioassay using technical grade insecticides, as described above. Graphical analysis was produced using GraphPad Prism 8.

\section{RESULTS}

Bromeliad survey. A county-wide operational survey of bromeliads was performed in Collier County to map bromeliad locations producing juvenile mosquitoes, the results of which are beyond the scope of this project and used solely for operational decision making. From May 2019 to October 2019 a total of 2267 juvenile mosquitoes were collected from large-tank bromeliads located in the Naples Botanical Garden. These collections comprised of three main genera - Aedes (Meigen, 1818), Culex (Linnaeus, 1758) and Wyeomyia (Theobald, 1901) (Table 1). 
From these genera, five main taxonomic units were identified (Table 1; Figure 1A), including Ae. aegypti, Ae. albopictus, Wyeomyia mitchellii (Theobald), Cx. nigripalpus (Theobald) and $C x$. quinquefasciatus. The most abundant species inhabiting bromeliads was Cx. quinquefasciatus, accounting for nearly $75 \%$ (CI 95\% 0.728-0.764) of all specimens collected (Table 1; Figure 1B). Cx. nigripalpus was the second most abundant, accounting for $15 \%$ (CI 95\% 0.0136-0.166) of the total specimens collected (Table 1; Figure 1B). Ae. albopictus, Ae. aegypti and Wy. mitchellii were the least abundant and comprised $5.6 \%$ (CI 95\% 0.049-0.068), $0.8 \%$ (CI 95\% 0.005-0.013) and 0.1\% (CI 95\% 0.000-0.003) of the total specimens collected, respectively (Table 1; Figure 1B). While five main taxonomic units were identified in total, species richness $(\mathrm{S})$ on any given collection day consisted of 3 to 4 (Table 1; Figure 1A), with the identification of the two least abundant species identified only once (Table 1). Cx. quinquefasciatus, Cx. nigripalpus and Ae. albopictus were the most common species identified throughout the collections.

Insecticide susceptibility tests. With $C x$. quinquefasciatus being the most abundant species in the gardens, the identification of pyrethroid resistance in Collier's Cx. quinquefasciatus mosquitoes (Lucas et al 2020), and the recent incorporation of pyrethroidbased insecticides into the Districts IPM program, we asked whether $C x$. quinquefasciatus from Naples Botanical Gardens also harbors pyrethroid resistance. Technical grade products corresponding to the active ingredients found in formulated products used by the District were chosen for the assay: d-phenothrin (Sumithrin), pyrethrum and naled. D-phenothrin and pyrethrum (pyrethrins) are active ingredients in the pyrethroidbased insecticides, Anvil 10-10 and Merus 3.0, respectively, and have been recently incorporated into the Districts adulticide program. Naled is the active ingredient of an organophosphate-based insecticide, Dibrom Concentrate, also used by the District.

Culex quinquefasciatus from the Naples Botanical Gardens had a high level of pyrethroid resistance with an average corrected percent mortality rate of $2.78 \%$ for technical grade pyrethrum (Figure 2A) and $5.13 \%$ for Merus 3.0 (Figure 2B) at the CDC diagnostic time of $45 \mathrm{~min}$. Further, average corrected percent mortality was $20.59 \%$ and $33.33 \%$ for technical grade d-phenothrin (Figure 2C) and Anvil 10-10 (Figure 2D), respectively. Mosquitoes were susceptible to the organophosphate naled, with complete mortality using both the technical grade and formulated product for naled at the CDC diagnostic time of $45 \mathrm{~min}$ (Figure 2E-F). Taken together these data signify that $C x$. quinquefasciatus mosquitoes collected from ornamental bromeliads of the Naples Botanical Gardens are resistant to pyrethroid-based insecticides, but not organophosphate-based materials. The published CDC diagnostic dose for Cx. quinquefasciatus and CDC diagnostic times for technical grade insecticides were used as reference, as previously described (Lucas et al 2020). While using the technical grade pyrethrum CDC diagnostic time for Merus 3.0 may present a flaw in our comparisons, it is important to note that assays using Merus 3.0 displayed roughly $40 \%$ mortality even at the $2 \mathrm{~h}$ timepoint.

At this time, resistance status of other species identified within the gardens has not been assayed. Resistance status of Ae. aegypti within the District is well known (unpublished data; Estep et al 2018) and operational concerns regarding pyrethroid-resistance in Cx. nigripalpus, Ae. albopictus and Wyeomyia spp have not surfaced.

Detection of knockdown resistance. Recent studies on Collier's Cx. quinquefasciatus has shown presence of the $k d r$ mutation, L1014F, and phenotypic expression of knockdown resistance in some parts of the county (Lucas et al 2020). We asked whether the Naples Botanical Garden Cx. quinquefasciatus collection harbors $k d r$-attributed resistance and if this has a significant impact on its pyrethroid resistance status. Phenotypic expression of knockdown resistance can be determined by evaluating a population for recovery $24 \mathrm{~h}$ post-treatment. After completion of the CDC bottle bioassay with technical-grade d-phenothrin and pyrethrum, Cx. quinquefasciatus were transferred 


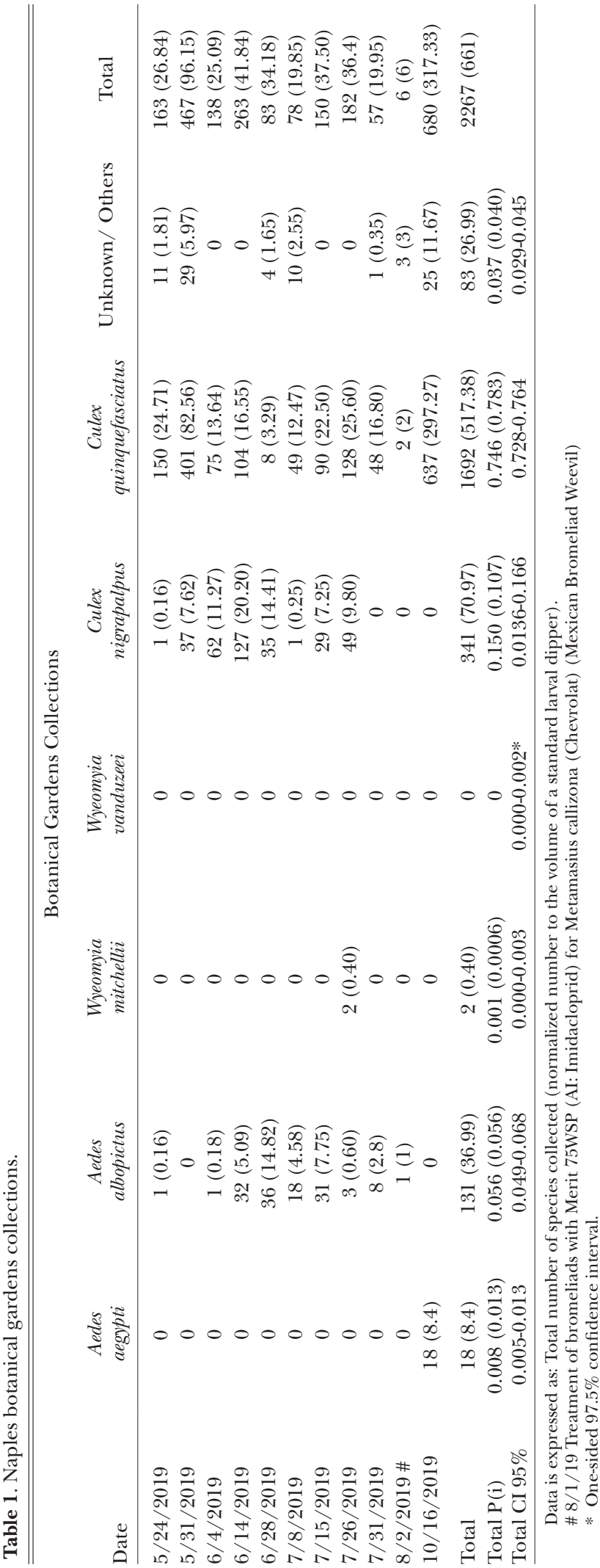


A

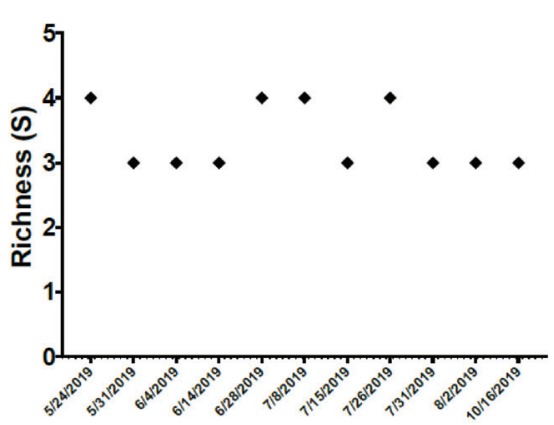

B

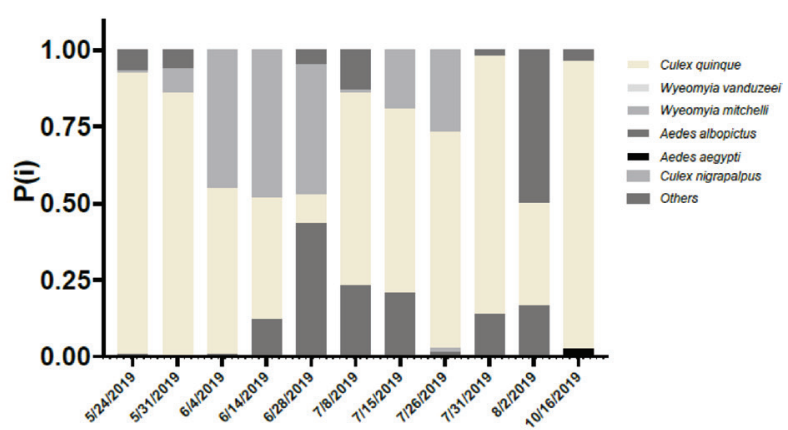

Figure 1. Bromeliad survey performed at the Naples Botanical Gardens, including species richness (A) and species abundance (B). Species richness (S) represents the number of mosquito species present. Species abundance $(\mathrm{P}(\mathrm{i}))$ represents the proportion of the total number of $\mathrm{i}^{\text {th }}$ species. Species richness and abundance were calculated in Microsoft Excel for each collection date.

to holding cages and assessed for recovery $24 \mathrm{~h}$ post-exposure. With $2 \mathrm{~h}$ of exposure to pyrethrum and d-phenothrin, Cx. quinquefasciatus collected from Naples Botanical Gardens reached a knockdown of $44.34 \%$ and $45.93 \%$ (Fig. 3A), respectively. After a $24 \mathrm{~h}$ recovery period, percent mortality was reduced for both technical grade materials (Fig. 3A). These results suggest that $C x$. quinquefasciatus from Naples Botanical Garden may display phenotypic characteristics of $k d r$-associated pyrethroid resistance. Genotyping of the gardens $C x$. quinquefasciatus collections for $k d r$ mutations, such as the leucine (L) to phenylalanine (F) substitution at residue 1014 (L1014F), within the voltagegated sodium channel gene would provide information regarding the presence or absence of these $k d r$ mutations. However, phenotypic expression of $k d r$ mutations through recovery assays performed in this study provides information regarding potential operational significance.

Detection of metabolic resistance. To assess the role of metabolic resistance mechanisms on the resistance status of Naples Botanical Garden Cx. quinquefasciatus, mosquitoes were treated with synergists to inhibit oxidase (PBO), esterase (DEF), or glutathione transferase (DEM) activity. After exposure to the synergist PBO, Naples Botanical Garden Cx. quinquefasciatus mosquitoes displayed a rescue of the resistant phenotype observed with exposure to pyrethrum only at the CDC diagnostic time of $45 \mathrm{~min}$. Exposure of Naples Botanical Garden Cx. quinquefasciatus to $\mathrm{PBO}$ prior to CDC bottle bioassay using pyrethrum resulted in $94.12 \%$ mortality, while pyrethrum alone resulted in $2.28 \%$ mortality at diagnostic time (Fig. 3BC). Treatment with DEF resulted in a partial reduction of the resistant phenotype with a mortality of $25.41 \%$ at diagnostic time (Fig. 3B-C). Treatment with DEM was similar to pyrethrum only, and resulted in a mortality of $3.80 \%$ at diagnostic time (Fig. 3B-C). Together these results suggest that oxidase activity plays the primary role in the pyrethroid resistance status of Naples Botanical Garden Cx. quinquefasciatus, while esterase activity may play partial role in resistance within this field collection.

\section{DISCUSSION}

Monitoring resistance status is essential for the selection of proper control methods to target vector species. It was recently reported that Ae. aegypti populations in Florida, including in Collier County, exhibit a high frequency of $k d r$ mutations and increased pyrethroid resistance (Estep et al 2019). Furthermore, field collections of $C x$. quinquefasciatus from highly urbanized areas within Collier County, have been shown to be resistant to pyrethroid-based control materials - resistance being associated with oxidase and esterase metabolic process, and 
A

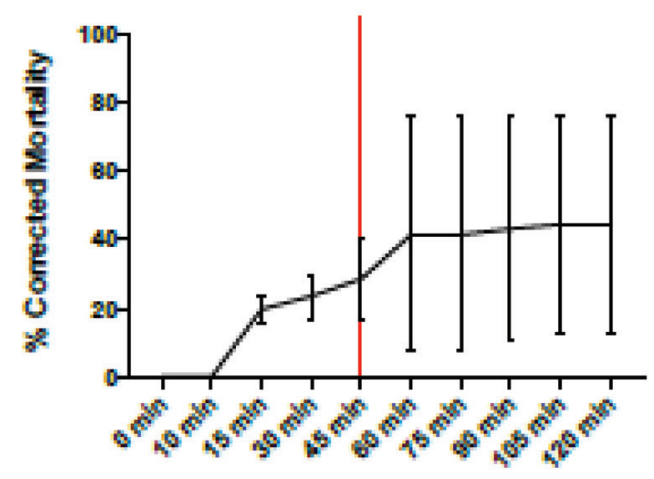

C

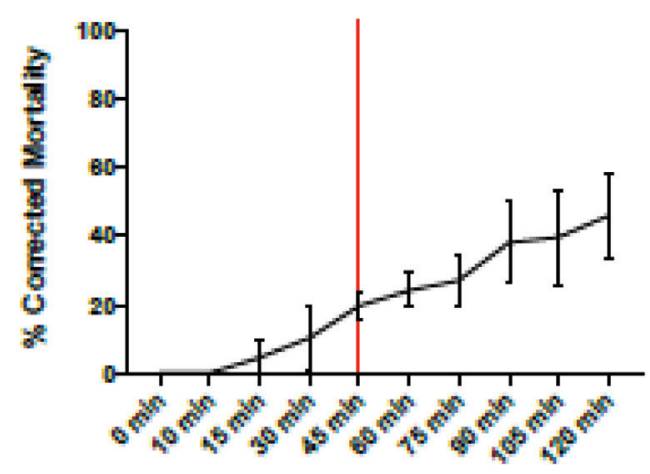

$\mathbf{E}$

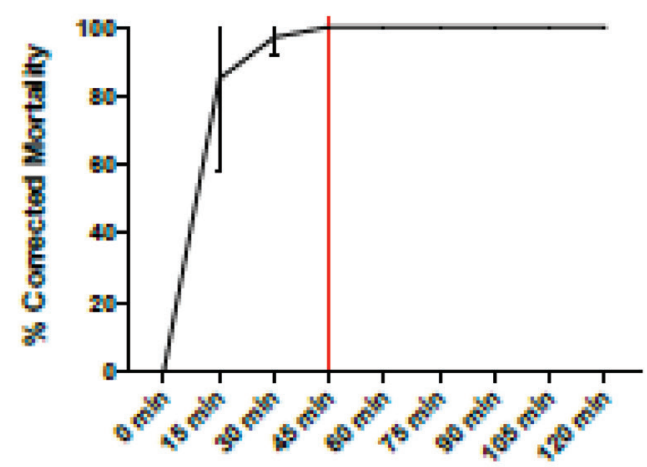

B

Merus 3.0

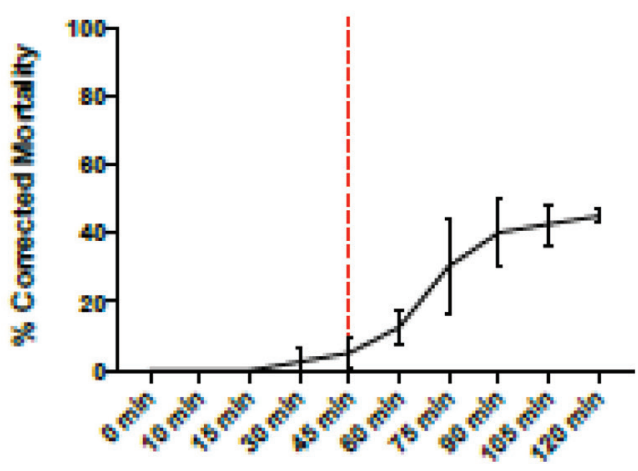

D

Anvill 10-10

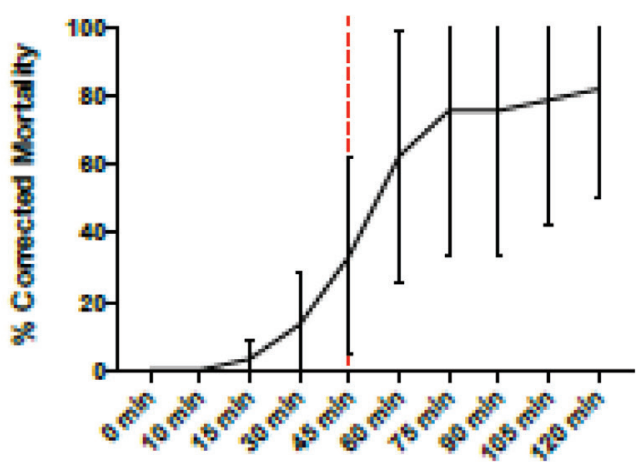

$\mathbf{F}$

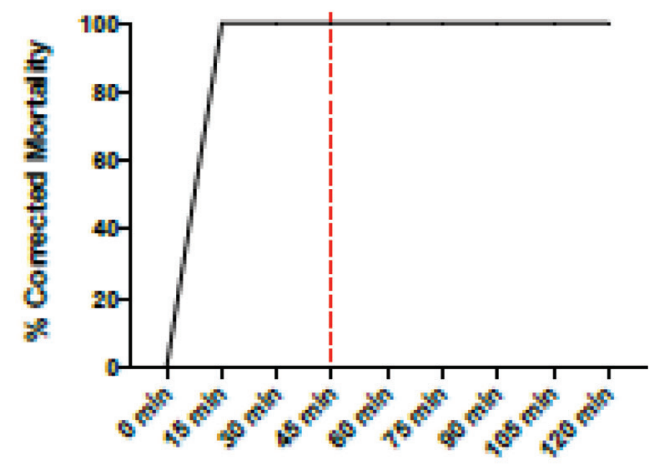

Figure 2. Centers for Disease Control and Prevention (CDC) bottle bioassays for Cx. quinquefasciatus collected from the Naples Botanical Gardens. CDC bottle bioassays using technical-grade insecticides: (A) $15 \mu \mathrm{g} / \mathrm{ml} \mathrm{pyre}-$ thrum, (C) $22 \mu \mathrm{g} / \mathrm{ml}$ d-phenothrin (Sumithrin ${ }^{\circledR}$ ), and (E) $2.25 \mu \mathrm{g} / \mathrm{ml}$ naled. CDC bottle bioassays using formulated products: (B) Merus $2.0 \AA$, (D) Anvil 10-10®, and (F) Dibrom ${ }^{\circledR}$ Concentrate. Each formulated product was diluted in acetone to yield the equivalent CDC diagnostic dose of active ingredient per bottle. Solid vertical red line indicates published threshold for CDC diagnostic dose of the susceptible Cx. quinquefasciatus Sebring colony. Threshold times for formulated products (dashed vertical red lines) are unknown but provided for reference. Data represent 3 technical replicates and are shown as mean \pm SD. 

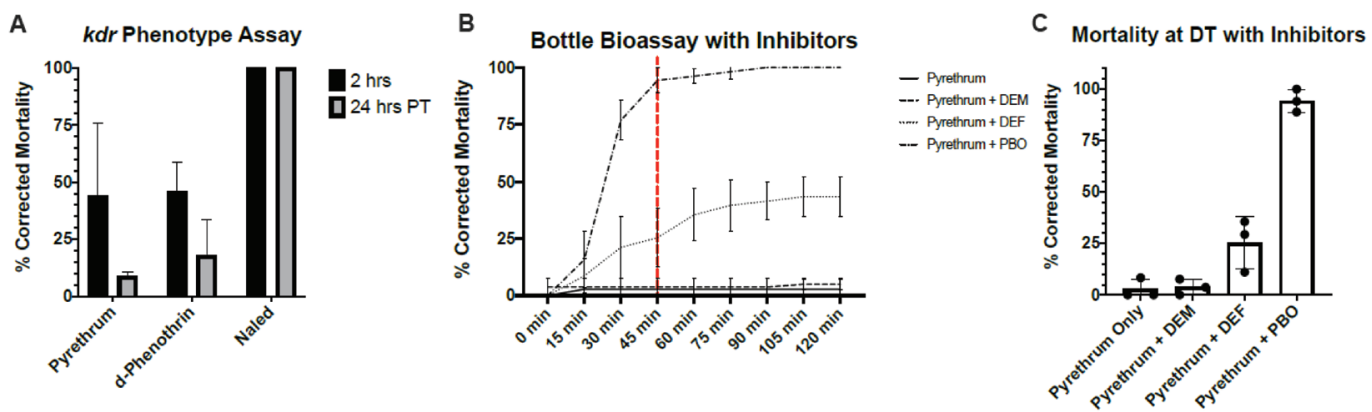

Figure 3. Identification the pyrethroid resistance mechanism including knockdown $(k d r)$ and metabolic resistance. (A) Phenotypic expression of knockdown resistance in Cx. quinquefasciatus mosquitoes collected from the Naples Botanical Garden. Percent recovery at $2 \mathrm{~h}$ postexposure for Cambier Park and Sabal Palm. Data represent 3 technical replicates and are shown as mean \pm SD. (B-C) Centers for Disease Control and Prevention (CDC) bottle bioassay using $15 \mu \mathrm{g} / \mathrm{ml}$ pyrethrum in conjunction with exposure to 1 of 3 synergists: S.S.S-tributylphosphorotrithioate (DEF) $(125 \mu \mathrm{g}$ /bottle), diethyl maleate (DEM) $(80 \mu \mathrm{g} /$ bottle), and piperonyl butoxide $(\mathrm{PBO})(400 \mu \mathrm{g} /$ bottle), which inhibits oxidase activity. Data represent 3 technical replicates and are shown as mean \pm SD. (B) Dashed vertical red line indicates published threshold for CDC diagnostic dose of the susceptible Cx. quinquefasciatus Sebring colony.

$k d r$ mutations (Lucas et al 2020). Merus 3.0, which uses $5 \%$ pyrethrins as an active ingredient, is currently being utilized in the Districts rotary-wing aircraft targeting smaller adulticiding treatment blocks. The Naples Botanical Garden often falls within these treatment blocks. With the on-going threat of vector borne disease, including West Nile virus, in Southwest Florida, it is imperative to understand the effectiveness of pyrethroidbased adulticides on vector species in these areas, and in particular, high-traffic and tourist dense locations.

Our survey for vector species inhabiting the exotic bromeliad collections of the Naples Botanical Gardens identified the presence of Cx. quinquefasciatus, Ae. aegypti, Ae. albopictus and Cx. nigripalpus. As the most abundant disease vector identified within the gardens, we asked whether our current adulticiding methods utilizing pyrethroidbased control materials would effectively reduce $C x$. quinquefasciatus population numbers in the area. We identified pyrethroid resistance in Cx. quinquefasciatus collected from Naples Botanical Gardens, and that oxidase activity was the primary mechanism responsible for its pyrethroid resistance status. Furthermore, esterase activity and resistance attributed to $k d r$ mutations may also play a role in Naples Botanical Gardens $C x$. quinquefasciatus resistance status. These re- sults are consistent with our previous studies of nearby field collections of Cx. quinquefasciatus from Cambier Park, an urban locality within the District (Lucas et al, 2020).

Anvil 10-10 contains the synergist PBO, and may serve as a more efficacious product against $C x$. quinquefasciatus harboring pyrethroid resistance attributed to oxidase activity. While mortality at diagnostic time was $33.33 \%$ for Anvil 10-10, our CDC bottle bioassay results presented here indicated that Anvil 10-10 was more efficient than Merus 3.0 and d-phenothrin alone (Figure 2). Furthermore, after $2 \mathrm{~h}$ Anvil 10-10 had the highest mortality at just above $80 \%$ (Figure 2), suggesting that the $\mathrm{PBO}$ included in the formulation may play a role in its efficacy. However, if multiple resistant mechanisms are present within a mosquito population, such as esterase and $k d r$-associated resistance identified in the collections taken from the Naples Botanical Garden, then the inclusion of PBO may not be enough to rescue the pyrethroid-resistant phenotype. Vector control programs should consider multiple resistance mechanisms in relation to pyrethroid resistance identified in the field. Furthermore, bottle bioassay results may not be representative of field efficacy. If a synergized pyrethroid-based product is being considered for targeting pyrethroid resistant mosquitoes then cage trials should be performed to ensure efficacy. 
Independent of wide area adulticiding practices by the local vector control agency, there are limited options to prevent vector mosquitoes from inhabiting ornamental bromeliads at the juvenile stage. Treatment using residual applications of adulticide to bromeliads have been shown to provide adequate control of Ae. albopictus (Bibbs et al 2018). The insect growth regulator (S)methoprene has been successful in controlling Ae. aegypti production within bromeliads (Ritchie and Broadsmith 1997). Furthermore, Bacillus thuringiensis israelensis (Bti), Bacillus sphaericus (BS) and Spinosad-based larvicides in granular, tablet and liquid form are also readily available. All these methods require "boutique" treatments of individual production sites, which may not be feasible for the vector control program. While public outreach may assist in the reduction peridomestic container breeding species (Healy et al 2014), it is impractical to solicit the removal of ornamental bromeliads in domestic habitats or halt conservation efforts for exotic and native bromeliads by botanical gardens. As such, identifying which adulticide materials are most suitable for controlling these species originating from such habitat is essential to a well-rounded IPM program. Through a robust IPM approach, including a combination the abovementioned control measures and public outreach, vector species inhabiting bromeliads can be reduced.

\section{ACKNOWLEDGMENTS}

The authors thank the Collier Mosquito Control District (CMCD) Board of Commissioners, Executive Director Patrick Linn and all the employees at CMCD who participated in sample collection and technical assistance. We also thank the staff at the Naples Botanical Gardens, including Cameron Cole, for providing CMCD access to their facility for this study. We also thank the CDC Southeastern Center of Excellence in Vector Borne Disease for providing funding for CMCD's research internship program. Further, we thank the CDC Division of VectorBorne Diseases for offering mosquito control districts with free Insecticide Resistance
Kits and guidelines for assessing insecticide resistance and resistance mechanism evaluations.

\section{REFERENCES CITED}

Abbott WS. 1925. A method of computing the effectiveness of an insecticide. JEcon Entomol 18, 265-267.

Bibbs CS, Crosier JE, D'Amato JM, Gibson-Corrado J, Xue RD. 2018. Bromeliad targeted foliar treatments with Aqualuer ${ }^{\circledR}$ 20-20 for hot spot mitigation using three hand sprayers against Aedes albopictus (Diptera: Culicidae). J Vector Ecol. 43, 215-219.

Blackmore CG, Stark LM, Jeter WC, Oliveri RL, Brooks RG, Conti LA, Wiersma ST. 2003. Surveillance results from the first West Nile virus transmission season in Florida, 2001. Am J Trop Med Hyg. 69, 141-150.

Brogdon WG, Chan A. 2010. Guidelines for evaluating insecticide resistance in vectors using the CDC bottle bioassay. Atlanta, GA: Centers for Disease Control and Prevention.

Brogdon WG, McAllister JC. 1998a. Simplification of adult mosquito bioassays through use of time-mortality determinations in glass bottles. J Am Mosq Control Assoc. 14, 159-164.

Brogdon WG, McAllister JC. 1998b. Insecticide resistance and vector control. Emerg Infect Dis. 4, 605-613.

CDC [Centers for Disease Control and Prevention]. 2017. Insecticide resistance [Internet]. Atlanta, GA: Centers for Disease Control and Prevention [accessed July 03, 2017]. Available from: https://www. cdc.gov/zika/vector/insecticide-resistance.html

CDC [Centers for Disease Control and Prevention]. 2020. CONUS Manual for evaluating insecticide resistance in mosquitoes using the CDC Bottle Bioassay Kit. [accessed March 01, 2019]. Available from: https://www.cdc.gov/zika/vector/insecticide-resistance.html

Estep AS, Sanscrainte ND, Waits CM, Bernard SJ, Lloyd AM, Lucas KJ, Buckner EA, Vaidyanathan R, Morreale R, Conti LA, Becnel JJ. 2018. Quantification of permethrin resistance and $k d r$ alleles in Florida strains of Aedes aegypti (L.) and Aedes albopictus (Skuse). PLoS neg. trop. Dis. 12, e0006544.

FLDOH [Florida Department of Health]. 2020. Mosquito-Borne Disease Surveillance [Internet]. Florida, United States of America: Florida Department of Health [accessed August 11, 2020]. Available from: http://www.floridahealth.gov/diseases-and-conditions/mosquito-borne-diseases/surveillance.html

Graham AS, Pruszynski CA, Hribar LJ, DeMay DJ, Tambasco AN, Hartley AE, Fussel EM, Michael SF, Isern S. 2011. Mosquito-associated dengue virus, Key West, Florida, USA, 2010. Emerg Infect Dis. 17, 2074-2075.

Harwood RF, James MT, Herms WB. 1979. Entomology in human and animal health. 7th edition. New York, NY: Macmillan.

Healy K, Hamilton G, Crepeau T, Healy S, Unlu I, Farajollahi A, Fonseca DM. 2014. Integrating the public in mosquito management: active education by community peers can lead to significant reduction in peridomestic container mosquito habitats. PLoS One. 9, e108504.

Lucas KJ, Bales RB J, McCoy K, Weldon C. 2020. Oxidase, Esterase, and $k d r$-associated pyrethroid resistance in Culex quinquefasciatus field collections of 
Collier County, Florida. J Am Mosq Control Assoc. 36, 22-32.

McAllister JC, Porcelli M, Medina JM, Delorey MJ, Connelly C, Godsey MS, Panella NA, Dzuris N, Boegler KA, Kenney JL, Kothera L, Vizcaino L, Lenhard AE, Mutebi JP, Vasquez C. 2020. Mosquito Control Activities during Local Transmission of Zika Virus, Miami-Dade County, Florida, USA, 2016. Emerg Infect Dis. 26, 881-890.

Ritchie SA, Broadsmith G. 1997. Efficacy of ALTOSID pellets and granules against Aedes aegypti in ornamental bromeliads. J Am Mosq Control Assoc.13, 201-2.

WHO [World Health Organization]. 2013. Test procedures for insecticide resistance monitoring in malaria vector mosquitoes [Internet]. Geneva, Swit- zerland: World Health Organization [accessed July 03, 2017]. Available from: https://www.who.int/malaria/publications/atoz/9789241511575/en/

Wilke ABB, Vasquez C, Mauriello PJ, Beier JC. 2018. Ornamental bromeliads of Miami-Dade County, Florida are important breeding sites for Aedes aegypti (Diptera: Culicidae). Parasit Vectors. 11, 283.

Wilke ABB, Chase C, Vasquez C, Carvajol A, Medina J, Petrie WD, Beier JC. 2019. Urbanization creates diverse aquatic habitats for immature mosquitoes in urban areas. Sci Rep. 9, :15335.

Wilke A, Vasquez C, Carvajal A, Medina J, Chase C, Cardenas G, Mutebi JP, Petrie WD, Beier JC. 2020. Proliferation of Aedes aegypti in urban environments mediated by the availability of key aquatic habitats. Sci Rep, 10, 12925. 